\title{
La taula d'avaluació. Una alternativa a la llibreta de notes
}

\author{
Eva Garcia, Col.legi Vedruna de Malgrat de Mar \\ Isabel Gaitan, IES Sa Palomera, Blanes \\ isabel.gaitan@gmail.com
}

Un full de càlcul serveix com a taula d'avaluació on s'hi preveuen les activitats a avaluar i el seu pes en a nota, així com les d'ampliació i reforç i el procés de recuperació.

Tots tenim al cap la imatge del professor sempre abraçat a la seva llibreta de notes. Però ara que la informàtica ens permet tantes possibilitats, potser ha arribat el moment de canviar. Us volem presentar un taula d'avaluació feta amb l'Excel, que permet englobar en molt poc espai moltíssima informació dels nostres alumnes.

El procés d'ensenyament-aprenentatge ha d'anar necessàriament acompanyat d'un mètode d'avaluació que permeti, de manera sistemàtica i pràctica, incorporar i enregistrar la gran diversitat d'activitats que es duen a terme amb els alumnes, així com tots els elements que formen part d'aquest procés d'avaluació (objectius terminals, avaluacions inicials, recuperacions, atenció personalitzada, assistència a classe, etc.).

Fa deu anys que treballem per integrar tots dos procediments, el d'ensenyar-aprendre i el d'avaluar, de manera que constitueixin un tot. L'objectiu que perseguíem era poder començar les classes de qualsevol crèdit amb l'avaluació completament programada, dissenyada i, sobretot, resumida en una única taula d'avaluació (full de càlcul Excel). Cada taula d'avaluació representa un crèdit.

Alhora, la taula ens permet informar els alumnes, des de l'inici, sobre com serà exactament el seu procés d'avaluació, i facilitar-los en qualsevol moment del curs les dades sobre aquesta. Creiem que és molt important explicar bé als alumnes de què se'ls avaluarà i com.

\section{Què hi fem constar a la taula d'avaluació?}

En el mateix moment de programar els crèdits ja s'han de tenir ben clars quins aspectes dels continguts que estem programant (conceptuals, procedimentals i actitudinals) seran avaluats. La taula ha de contenir, doncs, el màxim d'informació útil per al procés d'avaluació, que ha de ser tan objectiu i just com sigui possible, $i$ ha d'incloure el seguiment $i$ l'atenció personalitzada cap a l'alumna/e.

Us detallem tot seguit cadascun dels ítems que fem constar a la taula:

- Els objectius terminals (2n nivell de concreció, especificats per normativa), que són la nostra referència per elaborar els objectius didàctics $i$ l'avaluació de cada unitat (3r nivell de concreció).

- Els dos blocs d'activitats, segons si són obligatòries o optatives:

Bloc 1. Activitats avaluables i que l'alumne haurà de fer obligatòriament (a la taula d'exemple escrites en negre);

Bloc 2. Activitats avaluables però que l'alumne podrà fer de manera optativa; n'hi haurà tant d'ampliació com de reforç (a la taula d'exemple escrites en blau). Només les convertirem en obligatòries en aquells casos en què l'alumne les necessiti per assolir els objectius.

- Les activitats concretes de cada bloc:

1. Activitats pràctiques (laboratori).

2. Activitats fetes a partir de recursos MAV (Mitjans Audiovisuals) i activitats fetes a partir de recursos TIC (Tecnologies de la Informació i la Comunicació).

3. Exàmens. 
4. Exercicis diversos (activitats, mapes conceptuals, resums, esquemes, pòsters, etc.)

5. Activitats relacionades amb les sortides trimestrals.

\section{- Els diferents tipus d'avaluacions:}

1. L'avaluació inicial, que ens donarà dades sobre els coneixements previs de l'alumna/e. Tenim en compte aquestes tres possibilitats: l'alumna/e té coneixements correctes sobre el tema (1), l'alumna/e té coneixements equivocats sobre el tema $(-1)$, l'alumna/e no té coneixements sobre el tema (0).

2. L'avaluació formativa i contínua. Recollirem les activitats que considerem necessàries (obligatòries i optatives) i les valorarem. És molt important que els alumnes coneguin els resultats d'aquestes avaluacions per tal de facilitar-los la millora de l'aprenentage. També caldrà que els professors valorem la programació que estem desenvolupant a classe, per tal d'ajustar els continguts i/o activitats en funció dels progressos dels nostres alumnes.

3. Finalment, l'avaluació sumativa ens donarà informació sobre les capacitats assolides per l'alumne/a i ens permetrà emetre una qualificació. En cas que l'alumna/e no hagués assolit els objectius, caldrà que la taula contempli les activitats que demanarem per tal que els pugui recuperar.

\section{- La ponderació dels diferents continguts:}

a) Valorem l'actitud de l'alumna/e (15\% de la nota final).

b) Valorem els procediments i conceptes que ha assolit l'alumna/e (85\% de la nota final). Aquesta valoració la ponderem d'aquesta manera: activitats de dificultat alta $\mathbf{7 0 \%}$ de la nota de procediments i conceptes) i activitats de dificultat mitjana (30\% de la nota de procediments i conceptes).

\section{Exemple de taula d'avaluació}

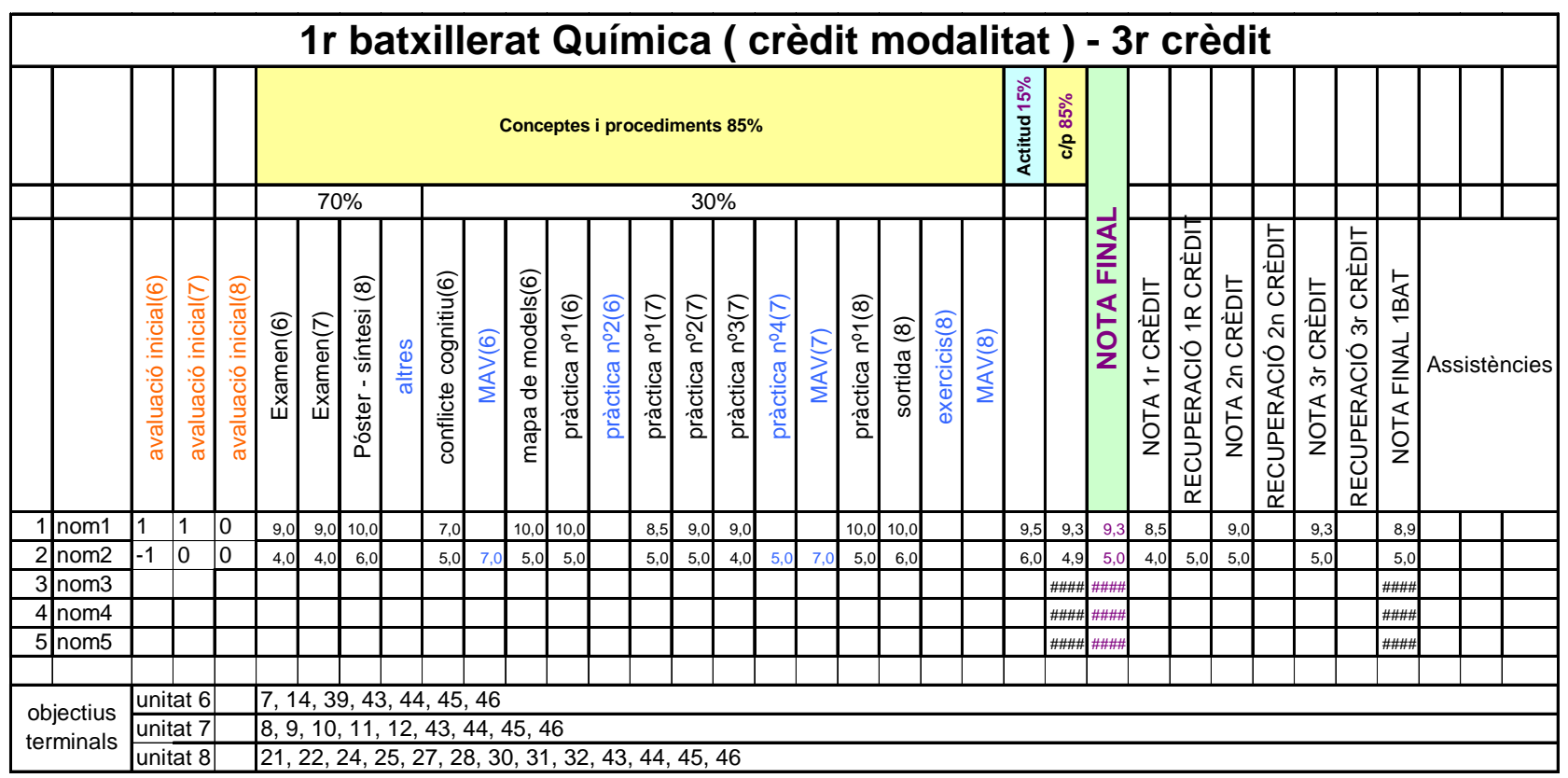

\section{Quina valoració en fem?}

La taula d'Excel, per mitjà de les fórmules introduïdes, ens permet tenir actualitzades en tot moment les notes de cada alumna/e i la nota final. Fins i tot hi podem recollir la nota dels anteri- ors crèdits, incloses les recuperacions, la qual cosa ens proporciona una visió global de l'alumna/e i possibilita una valoració de la seva evolució.

La flexibilitat de la taula fa que els percentatges decidits només siguin una proposta, modificable en tot moment. També hi podem afegir o treure 
columnes ja que, per molt que haguem programat, no coneixem encara el grup d'alumnes i hem d'estar oberts a qualsevol canvi.

La taula és el reflex del que realment és un aprenentatge significatiu: sempre partim de l'avaluació inicial i la tenim en compte a l'hora de fer la valoració final.

Atenció a la diversitat. A mesura que anem veient el progrés de cada alumne, podem anar adaptant la taula a cadascuna de les seves necessitats.
La taula ens facilita poder avaluar tant el nostre procés d'ensenyament com el procés d'aprenentatge dels nostres alumnes.

La taula permet, de manera pràctica i eficaç, treballar el tema de l'avaluació per Departaments, unificar criteris i compartir objectius terminals i activitats amb companys d'altres matèries.

L'Excel permet tot un seguit de possibilitats gràfiques que ens ajudaran a mostrar els resultats de manera més visual: gràfics de barres, de percentatges, gràfiques comparatives, etc. 